\title{
Pathologic Alterations of Canine and Feline Adrenal Glands
}

\author{
Nadja Herbach", Kirstin Wiele\#, Ulrike Konietschke\#, Walter Hermanns \\ Institute of Veterinary Pathology, Center for Clinical Veterinary Medicine of the Ludwig-Maximilians-University, \\ Munich, Germany \\ Email: *n.herbach@Imu.de
}

Received 5 April 2016; accepted 8 July 2016; published 11 July 2016

Copyright (C) 2016 by authors and Scientific Research Publishing Inc.

This work is licensed under the Creative Commons Attribution International License (CC BY).

http://creativecommons.org/licenses/by/4.0/

(c) (i) Open Access

\begin{abstract}
The aim of the study was to determine the frequency and age-dependency of adrenal changes in dogs and cats, which were dissected between 2004 and 2006 at the Institute of Veterinary Pathology, LMU Munich. The adrenal glands of 101 dogs and 159 cats were dissected free from adjacent tissue, weighed, lamellated perpendicular to its longitudinal axis and were embedded in paraffin and plastic for histologic inspection. Ageing cats most frequently showed accessory cortical nodules in the capsule, cortex and medulla, pigment deposition and shock bodies. The appearance of accessory cortical nodules and pigment deposition were linked to the age of the cats and that of shock bodies was linked to infectious diseases. Inflammatory alterations were rare and neoplastic changes were not observed. In dogs, the most frequent alterations were accessory cortical nodules in the capsule, cortex and medulla and circulatory disturbances and there was a significant linkage of the appearance of cortical nodules and pigment deposition and age. Metabolic, inflammatory and tumorous diseases were rarely observed in the dogs examined. In summary, cats and dogs show similar incidental alterations of the adrenals. Clinical relevant adrenal lesions such as atrophy or primary neoplasia were rarely diagnosed.
\end{abstract}

\section{Keywords}

Adrenal, Histology, Dog, Cat

\section{Introduction}

In cats and dogs, clinical relevant primary adrenal diseases are rare. Cases of hyperadrenocorticism due to pituitary or adrenal tumors are reported as well as primary sex-hormone producing adrenal tumors, hyperaldosteron-

\footnotetext{
"Corresponding author.

${ }^{\#}$ KA and UK contributed equally to this work.
} 
ism due to aldosterone producing tumors and hypoadrenocorticism due to idiopathic or trophic adrenocortical atrophy [1] [2].

Incidental findings include degenerative changes e.g. mineralization of the adrenal cortex, amyloidosis and hemorrhages. Adrenalitis occurs due to growth of bacteria (E. coli), fungi (Histoplasma capsulatum, Cryptococcus neoformans, Coccidioides immitis), protozoa (Toxoplasma gondii) and viruses. Accessory adrenocortical nodules, which are frequently observed in ageing cats, diffuse cortical hyperplasia or nodular hyperplasia of aging dogs, cats and horses, and adrenocortical tumors are sometimes difficult to distinguish from one another [2].

Alterations of the adrenal medulla are rarely described in domestic animals and include mineralization and pheochromocytoma [2].

Although a variety of adrenal lesions have been reported, the frequency or age-distribution of those alterations is rarely mentioned. Thus, the adrenal glands of cats and dogs, dissected at the Institute of Veterinary Pathology were examined and all alterations were documented and evaluated in consideration of age and sex as well as taking the cause of death or euthanasia into account.

\section{Material and Methods}

The adrenal glands of 159 cats and 101 dogs, which were submitted to the Institute of Veterinary Pathology, LMU Munich for necropsy were dissected free from adjacent tissue, weighed and fixed by immersion in $4 \% \mathrm{pa}-$ raformaldehyde for at least 24 hours, lamellated perpendicular to its longitudinal axis and embedded in paraffin and plastic [3]. Sections were routinely stained with hemosiderin and eosin as well as the Giemsa stain. Special stains for amyloid (Kongo red), hemosiderin (Turnbull blue), mineralization (von Kossa stain) and fibrous tissue (Masson trichrome) were performed where necessary. Age classes were defined as $<0.5$ years, 0.5 to 6 years, 7 to 13 years and $>13$ years for both species.

Data from all investigations were analyzed with respect to normal distribution by the Kolmogorov-Smirnov/ Lilliefors test. Statistical analysis of the linkage between parameters was carried out using Pearson's correlation test (rP) or Spearman's rank correlation test (rSp). Statistical analysis of the correlation between qualitative and quantitative parameters was accomplished by Pearson's chi-square test $\left(\chi^{2}\right)$. Means of parameters (multiple groups) with normal distribution were compared by one-way ANOVA with LSD post-hoc test (analysis of variance; least significant difference test); homogeneity of variances was assessed by Levene's test. Alternatively, the Mann-Whitney U test (two groups) and the Kruskal-Wallis test (multiple groups) were applied as nonparametric statistical tests. The effect of age was corrected by applying partial correlation analyses where indicated (rpart). Statistical analyses were performed using IBM SPSS statistics 22 (IBM Cooperation, USA). Data are expressed as means and SD.

\section{Results}

In the majority of cats and dogs, infectious diseases and tumors were the main cause of death or euthanasia. Sixty-four percent of the cats (102) and 26\% of the dogs examined suffered from infectious diseases, and 23\% of the cats and $45 \%$ of the dogs exhibited tumors anywhere in the body.

\subsection{Cats}

The 159 cats examined included 33 females, 35 males, 34 spayed, and 55 castrated cats. The gender of two animals was not recorded. The mean age of the examined cats was $6.1 \pm 5.9$ years (min 10 days, max 20 years). Twenty-eight animals were less than 0.5-year-old, 51 were between 0.5 and 6 years, 29 were between seven and 13 years and 25 animals were over 13 years of age. The age of 26 animals was not reported, 17 of which were counted as adult, 9 as unknown.

The mean body weight of cats was $3.0 \pm 1.6 \mathrm{~kg}$ (min $0.15 \mathrm{~kg}, 10$-day-old male Persian cat, max $7.50 \mathrm{~kg}$, 14-year-old castrated European short-hair cat). The body weight significantly correlated with age and neutering (age: $\mathrm{r}_{\mathrm{Sp}}=0.530, \mathrm{p}<0.001$, Table 1 ; neutering: $\left.\mathrm{r}_{\mathrm{Sp}}=0.533, \mathrm{p}<0.001\right)$. The body weights of castrated $(4.0 \pm 1.3$ $\mathrm{kg})$ and spayed cats $(3.3 \pm 0.9 \mathrm{~kg})$ were significantly higher than those of intact males $(2.1 \pm 1.8 \mathrm{~kg})$ and females $\left(2.0 \pm 1.3 \mathrm{~kg}\right.$ ), respectively (one-way ANOVA, $\left.\mathrm{p}<0.001, \mathrm{r}_{\mathrm{Sp}}=0.533, \mathrm{p}<0.001\right)$. When the effect of age was corrected by partial regression analysis, the linkage between neutering and body weight remained significant $\left(\mathrm{r}_{\mathrm{part}}=0.482, \mathrm{p}<0.001\right)$. 
Table 1. Body and adrenal weights of cats.

\begin{tabular}{cccc}
\hline Age group & Body weight $(\mathrm{kg})$ & Weight of adrenals $(\mathrm{g})$ & Relative weight of adrenals $(\%)$ \\
\hline$<0.5$ years $(28)$ & $0.66 \pm 0.47^{\mathrm{a}}$ & $0.19 \pm 0.10^{\mathrm{a}}$ & $0.034 \pm 0.017^{\mathrm{a}}$ \\
0.5 - 6 years $(51)$ & $3.33 \pm 1.03^{\mathrm{b}}$ & $0.68 \pm 0.27^{\mathrm{b}}$ & $0.021 \pm 0.010^{\mathrm{b}}$ \\
7 - 13 years $(29)$ & $4.28 \pm 1.13^{\mathrm{c}}$ & $0.49 \pm 0.18^{\mathrm{c}}$ & $0.012 \pm 0.004^{\mathrm{c}}$ \\
$>13$ years $(25)$ & $3.35 \pm 1.30^{\mathrm{b}}$ & $0.51 \pm 0.17$ & $0.016 \pm 0.006^{\mathrm{bc}}$ \\
\hline
\end{tabular}

Data are means and SD, different superscripts indicate significant differences, (n) number of animals. Body weight, adrenal gland weight One-way ANOVA LSD Post hoc test, $\mathrm{p}<0.05$ was considered significant; relative weight of adrenals Kruskal Wallis Test, Mann Whitney U-Test with Bonferroni correction: $\mathrm{p}<0.01$ was considered significant.

The mean weight of both adrenal glands of cats was $0.51 \pm 0.27 \mathrm{~g}$, ranging from $0.05 \mathrm{~g}$ in a 14-day-old male British short-hair and a 0.25-year-old female European short-hair puppy to $1.82 \mathrm{~g}$ in a one-year-old female Wildcat. The maximum weight of the adrenals of domestic cats was $1.19 \mathrm{~g}$ (2.5-year-old castrated European short-hair cat). Adrenal gland weights significantly correlated with age (Table 1), body weight and neutering (age $r_{p}=0.453, p<0.001$, body weight $r_{p}=0.572, p<0.001$, neutering $r_{p}=0.306, p<0.001$ ). The absolute adrenal gland weight of castrated males $(0.65 \pm 0.21 \mathrm{~g})$ was significantly higher than that of intact males $(0.38 \pm$ $0.26 \mathrm{~g}, \mathrm{p}<0.001)$, intact females $(0.45 \pm 0.36 \mathrm{~g}, \mathrm{p}=0.001)$ and spayed females $(0.48 \pm 0.17 \mathrm{~g}, \mathrm{p}=0.002$; oneway ANOVA, LSD Post hoc test). When the effect of age was corrected by partial regression analysis, the linkage between neutering and adrenal gland weight remained significant $\left(r_{\text {part }}=0.273, p=0.002\right)$.

The adrenal gland-to-body-weight-ratio was $0.021 \% \pm 0.013 \%$, ranging from $0.004 \%$ in a 12 -year-old spayed European short-hair cat to $0.076 \%$ in a 0.08 -year-(14-day-) old male European short-hair puppy. Relative adrenal gland weights negatively correlated with age $\left(\mathrm{r}_{\mathrm{Sp}}=-0.509, \mathrm{p}<0.001\right)$ with animals under 0.5 years of age showing the highest adrenal gland-to-body-weight-ratio (Table 1). Relative adrenal gland weights were linked with neutering $\left(\mathrm{r}_{\mathrm{sp}}=-0.415, \mathrm{p}<0.001\right)$. Castrated males $(0.018 \% \pm 0.009 \%, \mathrm{p}=0.001)$ and spayed females $(0.015 \% \pm 0.007 \%, \mathrm{p}<0.001)$ showed significantly lower adrenal gland to-body-weight-ratios than intact males $(0.028 \% \pm 0.016 \%)$ and females $(0.027 \% \pm 0.014 \%)$, respectively (Kruskal-Wallis test $\mathrm{p}<0.001$, Mann-Whitney U-test with Bonferroni correction). When the effect of age was corrected by partial regression analysis, the linkage between neutering and relative adrenal gland weight remained significant $\left(\mathrm{r}_{\mathrm{part}}=-0.315, \mathrm{p}<0.001\right)$.

\subsubsection{Dystrophic and Degenerative Changes}

Lipid storage was observed in all adrenals of cats in varying degree and size of the lipid droplets. Large lipid droplets were observed in 156 of the 159 cats examined (Table 2).

Pigment deposition, cholesterol crystals and calcification were also frequently observed (Table 2). Finely granular to coarse mineralization of the adrenals and the fibrous capsule was observed in 38\% (60) of the feline adrenals (Figures 1-3). In early stages of mineralization, finely granular intracellular deposits appeared adjacent to apoptotic/necrotic cells. There was a significant linkage of cell death with calcification $\left(\mathrm{r}_{\mathrm{Sp}}=0.402, \mathrm{p}<0.001\right.$; $\left.\chi^{2}<0.001\right)$, deposition of cholesterol crystals $\left(\mathrm{r}_{\mathrm{Sp}}=0.863, \mathrm{p}<0.001, \chi^{2}=0.001\right)$, and pigment $\left(\mathrm{r}_{\mathrm{Sp}}=0.170 \mathrm{p}<\right.$ $\left.0.05, \chi^{2}=0.039\right)$ as well as inflammatory cell infiltration ( $\left.\mathrm{r}_{\mathrm{sp}}=0.324, \mathrm{p}<0.001, \chi^{2}=0.001\right)$. In addition, inflammatory cell infiltration of the adrenal cortex correlated with mineralization $\left(\mathrm{r}_{\mathrm{Sp}} 0.187, \mathrm{p}<0.05 ; \chi^{2}<0.05\right)$, cholesterol crystals $\left(\mathrm{r}_{\mathrm{Sp}} 0.164, \mathrm{p}<0.05 ; \chi^{2}<0.05\right)$ and pigment in cortical cells $\left(\mathrm{r}_{\mathrm{Sp}} 0.173, \mathrm{p}<0.05 ; \chi^{2}<0.05\right)$.

The occurrence of calcification, cholesterol crystals, pigment and large lipid droplets correlated with age of the cats (calcification: $\mathrm{r}_{\mathrm{Sp}}=0.173, \mathrm{p}=0.047, \chi^{2}=0.008$, cholesterol: $\mathrm{r}_{\mathrm{Sp}}=0.186, \mathrm{p}=0.032, \chi^{2}=0.002$, pigment: $\mathrm{r}_{\mathrm{Sp}}=0.736, \mathrm{p}<0.001, \chi^{2}<0.001$, large lipid droplets: $\mathrm{r}_{\mathrm{Sp}}=0.287, \mathrm{p}=0.001, \chi^{2}=0.004$, Spearman Rho Test/Pearson's Chi Square test, Table 3). There was a weak to moderate correlation of neutering and calcification, pigment and lipid storage (calcification: $\mathrm{r}_{\mathrm{Sp}}=0.169, \mathrm{p}=0.034$, pigment: $\mathrm{r}_{\mathrm{Sp}}=0.534, \mathrm{p}<0.001$, large lipid droplets: $r_{\mathrm{Sp}}=0.212, \mathrm{p}<0.01$ ) but when the effect of age was corrected by partial correlation analyses, only the linkage between pigment and neutering remained significant $\left(\mathrm{r}_{\mathrm{sp}}=0.273, \mathrm{p}<0.01\right)$.

Moderate hemosiderin deposition in the medulla was observed in a 15-year-old female ESC and adrenal amyloidosis was found in three cats (Figure 4, Table 2).

\subsubsection{Changes in Growth and Shape}

The second most frequent finding were nodules, located on, in or under the adrenal capsule (Table 2) and there 
Table 2. Summary of histological findings of adrenals of cats.

\begin{tabular}{|c|c|}
\hline Diagnosis & Number of animals \\
\hline Accessory cortical nodules, capsule & 108 \\
\hline Accessory cort. nodules, cortex/medulla & 44 \\
\hline Hyperemia cortex & 31 \\
\hline Hemorrhage & 15 \\
\hline Hyaline bodies & 51 \\
\hline Amyloidosis & 3 \\
\hline Calcification & 62 \\
\hline Lipid storage (large droplets) & 156 \\
\hline Cholesterol crystals & 73 \\
\hline Pigment & 80 \\
\hline Cell death & 78 \\
\hline Cortical atrophy & 4 \\
\hline Inflammatory cells cortex/medulla & $38 / 12$ \\
\hline Necrosis & 3 \\
\hline Cortical adenoma & 0 \\
\hline Pheochromocytoma & 0 \\
\hline Metastases & 8 (6 lymphoma, 2 carcinoma) \\
\hline
\end{tabular}

Table 3. Dystrophic changes and age of cats.

\begin{tabular}{|c|c|c|c|c|c|}
\hline Age group & Lipid cortex & Pigment cortex & Cholesterol cortex & Calcium cortex & Hemosiderin medulla \\
\hline$<0.5$ y (28) & $15(0 \%)$ & $1(4 \%)$ & $4(14 \%)$ & $5(17 \%)$ & $0(\%)$ \\
\hline $0.5-6$ y (51) & 44 (81\%) & 17 (33\%) & 30 (58\%) & 27 (52\%) & $0(\%)$ \\
\hline 7 - 13 y (29) & $23(98 \%)$ & $26(90 \%)$ & $13(44 \%)$ & $10(34 \%)$ & $0(\%)$ \\
\hline >13 y (25) & $22(100 \%)$ & $24(96 \%)$ & $13(52 \%)$ & $14(56 \%)$ & $1(4 \%)$ \\
\hline Adult (17) & $16(94 \%)$ & $7(41 \%)$ & $10(58 \%)$ & $5(29 \%)$ & $0(0 \%)$ \\
\hline
\end{tabular}

n number of animals.

was a significant linkage of the occurrence of those accessory capsular nodules and cell death $\left(\mathrm{r}_{\mathrm{sp}}=0.270, \mathrm{p}=\right.$ $\left.0.001, \chi^{2}=0.001\right)$. Accessory cortical nodules in the cortex and medulla were observed less frequently $(44 / 159$, Table 2). The occurrence of accessory adrenal cortical nodules in the adrenal cortex as well as fibrous tissue between cortex and medulla increased with age of the cats (accessory cortical nodules: $\mathrm{r}_{\mathrm{Sp}}=0.283, \mathrm{p}=0.001 / \chi^{2}$ $=0.009$, fibrous tissue: $\mathrm{r}_{\mathrm{Sp}}=0.705, \mathrm{p}<0.001, \chi^{2}<0.001$; Spearman Rho Test/Pearson's Chi Square test, Table 4). There was a weak to moderate correlation of sex and accessory cortical nodules and fibrous tissue between cortex and medulla. When the effect of age was corrected by partial correlation analyses, histological alterations were not linked to sex anymore.

Atrophy of the adrenal cortex was observed in four animals, hyperplasia of the adrenal zona glomerulosa was seen in two and of the zona fasciculata in three cats.

\subsubsection{Hemodynamic/Vascular Changes}

Hemodynamic/vascular changes were diagnosed in 10\% - 30\% of the animals examined and included hyperemia, hemorrhage and intravascular hyaline bodies (shock bodies, Figure 5, Table 2). Telangiectasia formation was observed in one female ESC which exhibited thrombosis of cardiac and lung vessels. There was a significant linkage between the occurrence of shock bodies and virus infections, including Parvo, Herpes, Calici and Corona virus infections $\left(\chi^{2}=0.006\right)$ as well as and with systemic infectious diseases in general (viral/bacterial; $\chi^{2}=$ 0.001). Sixty percent (95) of the cats with virus infections and 67\% (107) of the cats with systemic infections exhibited intravascular shock bodies. 


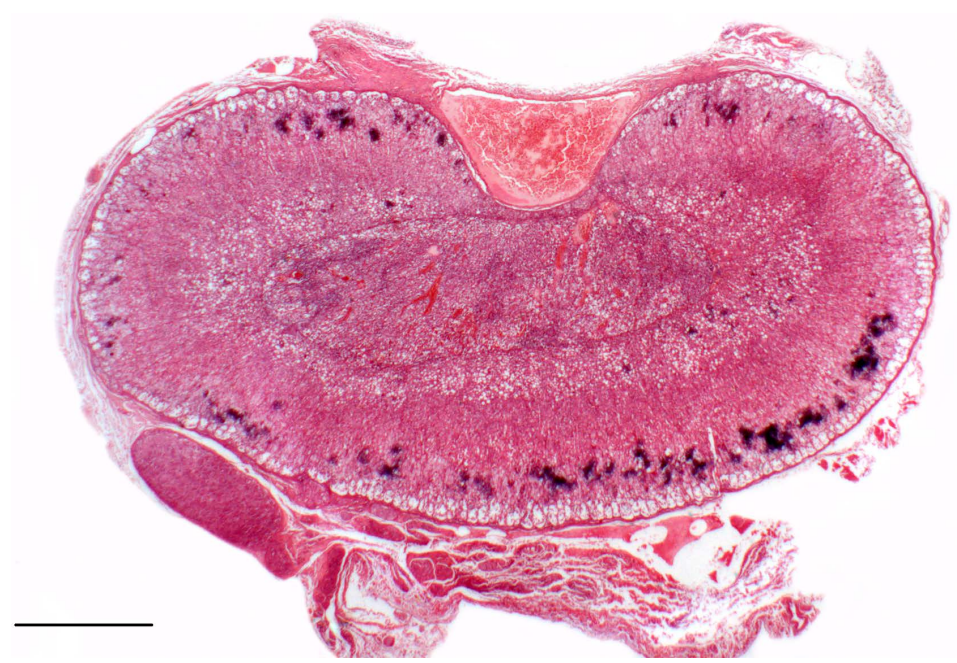

Figure 1. Calcification of the adrenal cortex, cat, H\&E stain, bar $1 \mathrm{~mm}$.

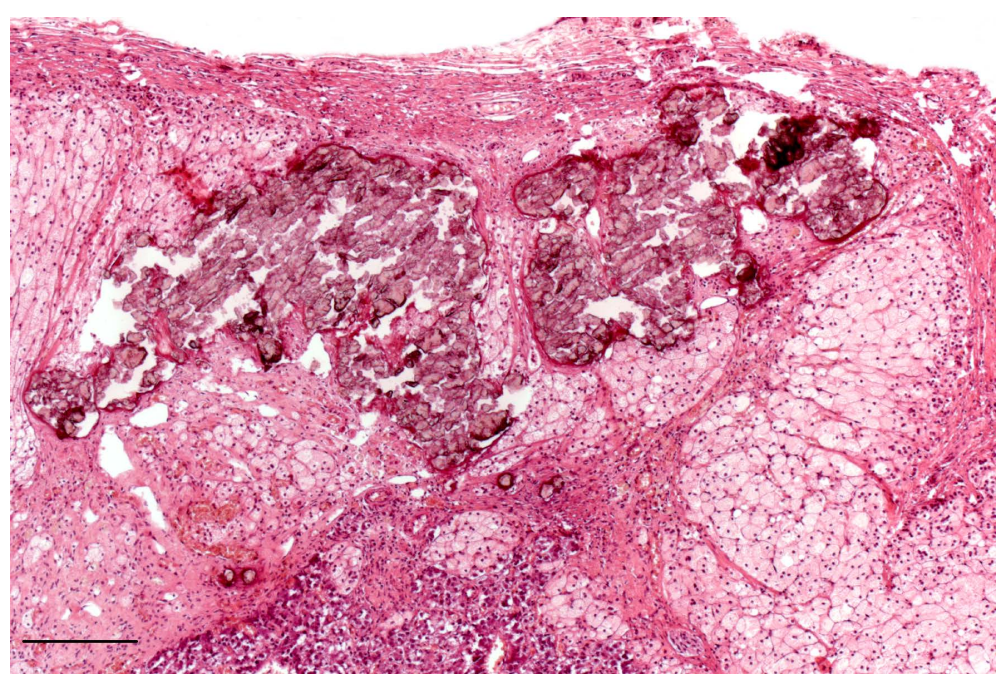

Figure 2. Calcification of the adrenal cortex, cat, H\&E stain, bar $200 \mu \mathrm{m}$.

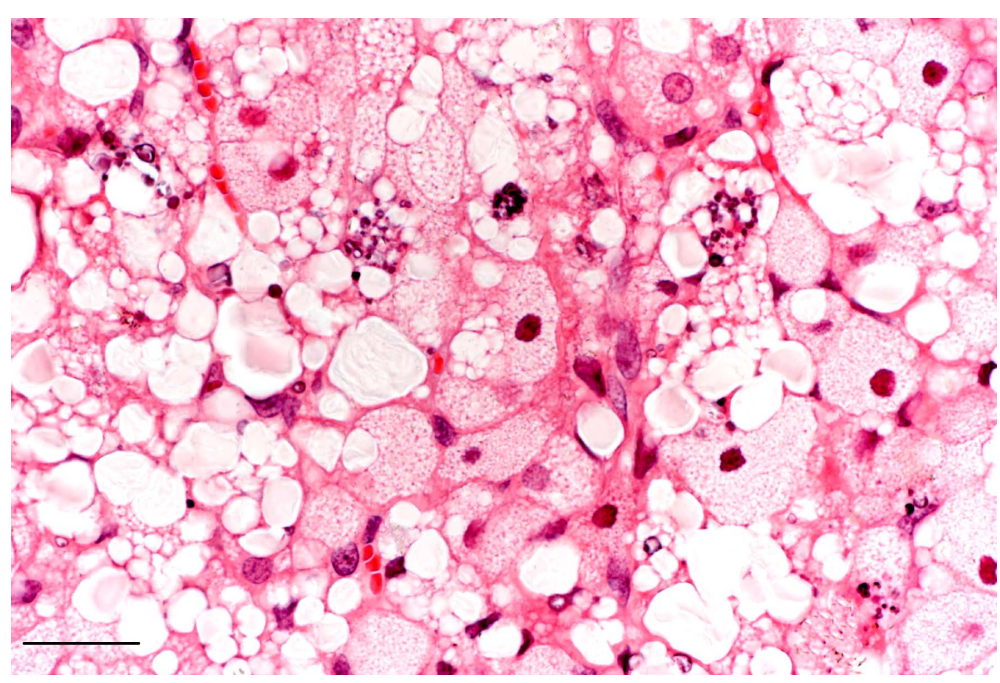

Figure 3. Intracellular calcification, cat, H\&E stain, bar $25 \mu \mathrm{m}$. 


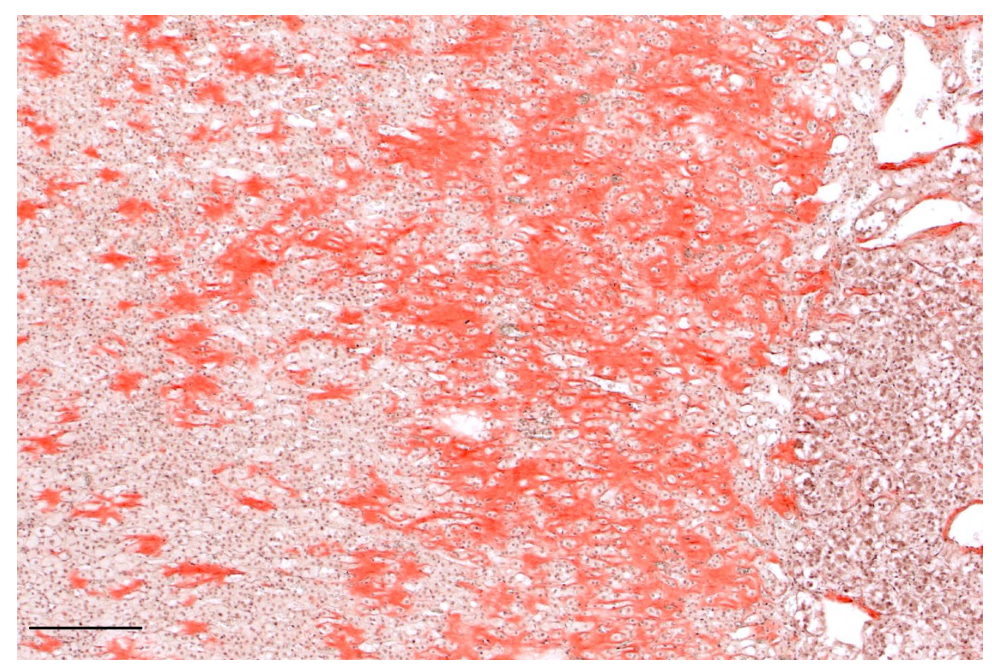

Figure 4. Amyloid deposition in the zona fasciculata and reticularis, cat, Kongo-red stain, bar $200 \mu \mathrm{m}$.

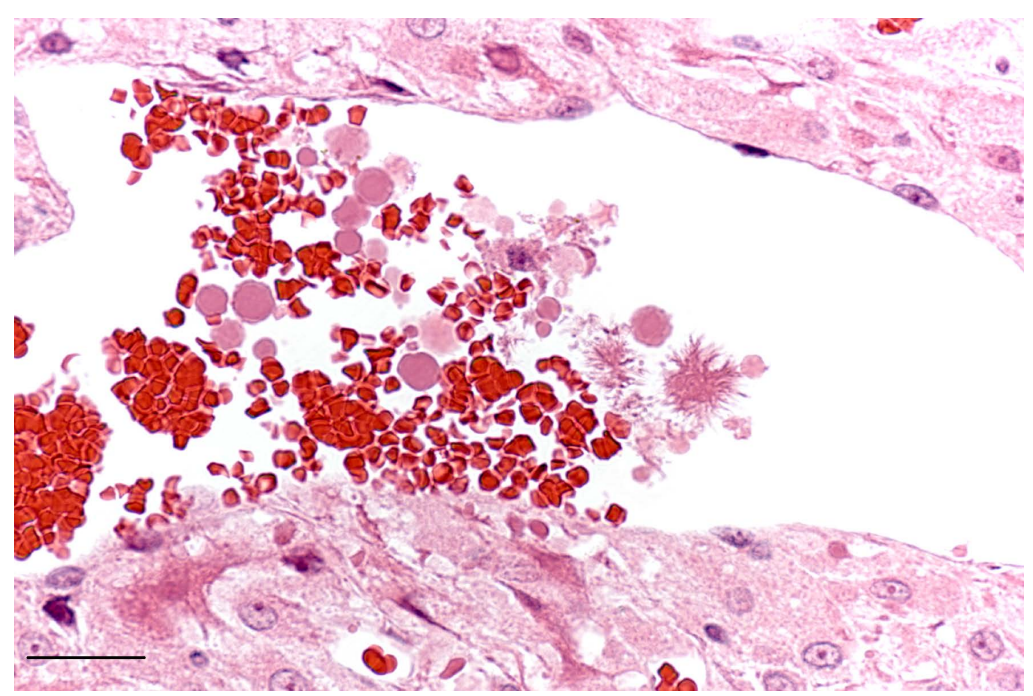

Figure 5. Intravasal shock bodies, cat, H\&E stain, bar $25 \mu \mathrm{m}$.

Table 4. Proliferative changes and age of cats.

\begin{tabular}{ccccc}
\hline Age group & Tumour anywhere & $\begin{array}{c}\text { Accessory nodules } \\
\text { capsule }\end{array}$ & $\begin{array}{c}\text { Accessory cortical nodules } \\
\text { (cortex/medulla) }\end{array}$ & Cortical hyperplasia \\
\hline$<0.5$ years $(28)$ & $0(0 \%)$ & $17(61 \%)$ & $1(4 \%)$ & $0(0 \%)$ \\
0.5 - 6 years $(51)$ & $3(6 \%)$ & $36(71 \%)$ & $15(29 \%)$ & $3(6 \%)$ \\
7 - 13 years $(29)$ & $13(44 \%)$ & $16(55 \%)$ & $11(37 \%)$ & $0(0 \%)$ \\
$>13$ years $(25)$ & $15(60 \%)$ & $19(76 \%)$ & $10(40 \%)$ & $0(0 \%)$ \\
Adult $(17)$ & $4(23 \%)$ & $13(76 \%)$ & $5(29 \%)$ & $2(12 \%)$ \\
\hline
\end{tabular}

n number of animals.

\subsubsection{Inflammation}

Inflammatory cell infiltration was frequently observed (38 times in the cortex, 17 times in the medulla, 9 times both cortex and medulla, Table 2). The infiltrates in the cortex and medulla consisted mainly of lymphocytes and plasma cells (29 and 8 times, respectively) or of neutrophilic granulocytes (18 and 12 times, respectively). 
About half the cats with corona virus infection (FIP) exhibited inflammatory cell infiltration in the adrenal cortex, one cat showed infiltrates in the medulla only. In one instance, infiltrates were associated with focal calcification of the cortex. One cat exhibited a diffuse infiltration of both adrenals with eosinophilic granulocytes (Figure 6) and another animal exhibited widespread necrosis with inflammatory cell infiltration of both adrenals; a malassimilation syndrome due to chronic bowel disease was diagnosed in the latter case.

\subsubsection{Tumors}

Primary adrenal tumors of the cortex and medulla were not observed in the cats examined in this study. The adrenals of six cats with malignant lymphoma and two cats with lung or pancreatic carcinoma exhibited metastases in the adrenals (Table 2).

\subsection{Dogs}

The 101 dogs examined included 39 males, 27 females, 19 spayed and 16 castrated dogs. The mean age of the animals was $7.7 \pm 4.4$ years (min 1 day, max 16 years). Six animals were less than 0.5 years of age, 32 were between 0.5 and 6 years, 53 were between 7 and 13 years and 9 animals were over 13 years of age. The age of a female adult Chihuahua was not reported.

The mean body weight was $21.7 \pm 13.1 \mathrm{~kg}$ (min $0.3 \mathrm{~kg}$ in a 1-day-old female mongrel puppy, max $54 \mathrm{~kg}$ in a 4-year-old female Great Dane). Sixty dogs were over $20 \mathrm{~kg}$, 34 were small breeds up to $20 \mathrm{~kg}$. Sex and neutering was not linked to body weight.

The mean weight of both adrenal glands of dogs was $2.6 \pm 1.6 \mathrm{~g}$, ranging from $0.1 \mathrm{~g}$ in a 1-day-old male mongrel puppy to $7.6 \mathrm{~g}$ in an eleven-year-old female Alsatian. Adrenal gland weights correlated with age class and body weight $\left(r_{p}=0.366, p<0.001 ; r_{p}=0.662 p<0.001\right.$; Table 5$)$. Dogs under 0.5 years of age showed the lowest adrenal gland weights. Castrated males showed significantly higher adrenal gland weights than the other gender (castrated male $3.9 \pm 1.7$ g vs. male $2.3 \pm 1.3 \mathrm{~g}, \mathrm{p}<0.002$ vs. female $2.8 \pm 2.1 \mathrm{~g}, \mathrm{p}<0.046$ vs. spayed female $2.1 \pm 1.1 \mathrm{~g} \mathrm{p}<0.002$, one-way ANOVA, LSD Post hoc test).

The adrenal gland-to-body-weight-ratio was $0.0148 \% \pm 0.009 \%$, ranging from $0.004 \%$ in a 3-year-old female beagle to $0.047 \%$ in a newborn female mongrel puppy. Animals under 0.5 years of age showed the highest adrenal gland-to-body-weight-ratio (Table 5). Age and neutering was not correlated to relative adrenal gland weight.

\subsubsection{Dystrophic and Degenerative Changes}

Intracellular pigment was observed in $86 \%$ of the dogs examined and appeared mainly in the zona reticularis and fasciculata, but rarely in the zona glomerulosa. Hemosiderin was detected in the adrenals of $21 \%$ of the dogs (15\% in the cortex, $6 \%$ in the medulla and $4 \%$ in cortex and medulla. Amyloid deposition was found in the zona reticularis and, in severe cases, the zona fasciculata of four Shar-Peis. Calcification was observed in the capsule

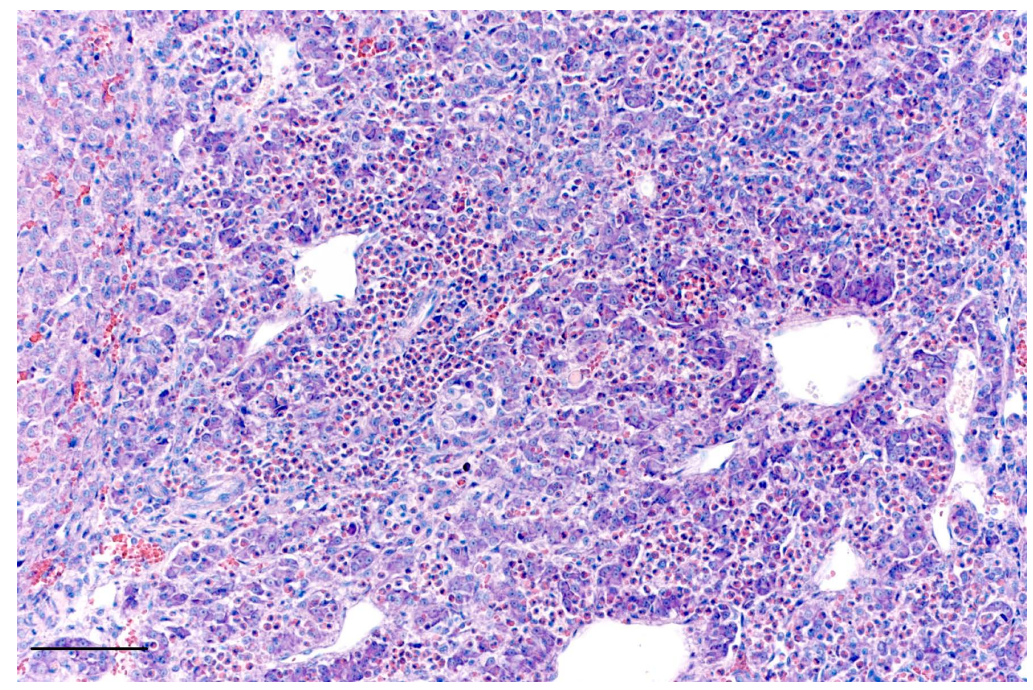

Figure 6. Eosinophilic adrenalitis, cat, H\&E stain, bar $100 \mu \mathrm{m}$. 
Table 5. Absolute and relative weights of the adrenal glands of dogs.

\begin{tabular}{|c|c|c|c|}
\hline Age group & Body weight (kg) & Weight of adrenals (g) & Relative weight of adrenals (\%) \\
\hline$<0.5$ years $(6)$ & $2.0 \pm 1.5^{\mathrm{a}}$ & $0.6 \pm 0.4^{\mathrm{a}}$ & $0.033 \pm 0.009^{\mathrm{a}}$ \\
\hline $0.5-6$ years $(31)$ & $23.7 \pm 12.7^{\mathrm{b}}$ & $2.3 \pm 1.2^{\mathrm{b}}$ & $0.011 \pm 0.004^{\mathrm{b}}$ \\
\hline 7 - 13 years (53) & $24.2 \pm 12.6^{\mathrm{b}}$ & $3.1 \pm 1.8^{\mathrm{c}}$ & $0.014 \pm 0.009^{\mathrm{ab}}$ \\
\hline >13 years $(9)$ & $15.2 \pm 7.8^{\mathrm{c}}$ & $2.7 \pm 1.0^{\mathrm{bc}}$ & $0.015 \pm 0.006^{\mathrm{ab}}$ \\
\hline
\end{tabular}

Data are means and SD, different superscripts indicate significant differences, (n) number of animals. Body weight, adrenal gland weight one-way ANOVA LSD Post hoc test, $\mathrm{p}<0.05$ was considered significant; relative weight of adrenals Kruskal Wallis Test, Mann Whitney U-Test with Bonferroni correction: $\mathrm{p}<0.01$ was considered significant.

and blood vessels of 7 dogs (Table 6). The presence and degree of pigment deposition in the cortex $\left(\mathrm{r}_{\mathrm{P}}=0.536 \mathrm{p}\right.$ $\left.<0.001, \chi^{2}<0.001\right)$, hemosiderin in cortex $\left(\mathrm{r}_{\mathrm{P}}=0.347 \mathrm{p}<0.001, \chi^{2}=0.001\right)$ and medulla $\left(\mathrm{r}_{\mathrm{P}}=0.275, \mathrm{p}=0.006\right.$, $\left.\chi^{2}=0.032\right)$, and calcification $\left(\mathrm{r}_{\mathrm{P}}=0.258, \mathrm{p}=0.010, \chi^{2}=0.011\right)$ correlated with age groups (Table 7). Eighty-one percent of the male dogs and $97 \%$ of the female dogs exhibited lipid containing pigment in the adrenal cortex $\left(r_{P}=0.218, p=0.029, \chi^{2}=0.029\right)$, and $10 \%$ of male and $\sim 30 \%$ of the female dogs exhibited pigment deposition in the medulla. Seven percent of the large dogs and $\sim 40 \%$ of dogs up to $20 \mathrm{~kg}$ exhibited lipid storage in the medulla $\left(r_{P}=0.384, p<0.001, \chi^{2}<0.001\right.$, Table 8).

\subsubsection{Changes in Growth and Shape}

The most frequent adrenal alterations of dogs were accessory cortical nodules on, in or under the surrounding fibrous capsule, occurring in 99/101 dogs (Table 6). Eighty-three of these dogs exhibited more than 3 cortical nodules in these locations. Fibrous septae, reaching from the adrenal capsule to the medulla, were evident in most dogs (87\%) and fibrous tissue between cortex and medulla was found $73 \%$ of the dogs examined. Accessory nodules composed mainly of zona fasciculata cells were found in the cortex of 48 animals, the medulla of 36 dogs and 19 dogs showed accessory nodules in both cortex and medulla. Atrophy of the zona fasciculata was observed in one 13-year-old female spayed poodle (Table 6). The occurrence of tumors anywhere in the body $\left(\mathrm{r}_{\mathrm{P}}=0.537, \mathrm{p}<0.001, \chi^{2}<0.001\right)$, accessory cortical nodules in the cortex $\left(\mathrm{r}_{\mathrm{P}}=0.309, \mathrm{p}=0.002, \chi^{2}<0.019\right)$, fibrous tissue between cortex and medulla ( $\mathrm{r}_{\mathrm{P}}=0.245, \mathrm{p}=0.014, \chi^{2}<0.001$ ), hyperplasia of the zona fasciculata $\left(\mathrm{r}_{\mathrm{P}}=0.251, \mathrm{p}=0.012, \chi^{2}<0.043\right)$ and glomerulosa $\left(\mathrm{r}_{\mathrm{P}}=-0.228, \mathrm{p}=0.023, \chi^{2}=0.005\right)$ correlated with age group (Table 9 ). Ninety percent of dogs over $20 \mathrm{~kg}$ and $\sim 60 \%$ of dogs up to $20 \mathrm{~kg}$ demonstrated fibrous tissue between cortex and medulla.

\subsubsection{Hemodynamic and Vascular Changes}

Hyperemia was evident in the adrenals of 79 dogs and more frequently involved the zona reticularis (36 times), than the zona fasciculata (20 times), or the medulla (17 times) and occurred only rarely in the zona glomerulosa (6 times). Different adrenal zones could be hyperemic at the same time, in most cases adjacent zones were hyperemic and 2 dogs showed diffuse hyperemia in all adrenal zones. Hemorrhage was found in the adrenal cortex of three dogs and extramedullary hematopoiesis was observed in five dogs. Hyaline shock bodies were detected mainly in medullary blood vessels of $10 \%$ of the dogs (Table 6).

\subsubsection{Inflammatory Changes}

Small foci of non-specific inflammatory cell infiltration of the adrenal cortex and medulla, consisting of mainly plasma cells and lymphocytes, were observed in $71 \%$ of the dogs. Fourteen dogs showed lympho-plasma cellular infiltration of both cortex and medulla and two animals of the medulla only. Multiple, large foci or diffuse infiltration with inflammatory cells were interpreted as adrenalitis, which was diagnosed in three animals (Table 6). One of these three animals, a female adult Chihuahua, exhibited severe eosinophilic adrenalitis. In three dogs, necrosis mainly of the adrenal cortex was observed, in a nine-year-old male dachshund with endocardiosis and a twelve-year-old female poodle with hepatopathy and glomerulonephritis, necrosis was accompanied by infiltration of the adrenal gland with neutrophilic granulocytes. A five-year-old spayed mongrel with torsion of the stomach and viral enteritis showed cortical necrosis without inflammatory reaction (Figure 7). 


\subsubsection{Tumors}

Adenomas of the adrenal cortex were observed in four dogs, a 13-year-old male Golden retriever, a 12-year-old female poodle, a nine-year-old castrated Alsatian mix and a 12-year-old female dachshund. Pheochromocytoma of the adrenal medulla was observed in one 10-year-old female Rottweiler (Figure 8, Figure 9). Metastases were evident in five dogs, one nine-year-old female mongrel exhibited metastases of a mamma carcinoma, a 16year-old male Poodle-mix and a 10-year-old female Husky showed adenocarcinoma of unknown origin. Adrenal involvement with malignant lymphoma was observed in two dogs (Table 6).

Table 6. Summary of histological findings of adrenals of dogs.

\begin{tabular}{cc}
\hline Diagnosis & Number of animals \\
\hline Accessory nodules capsule & 100 \\
Accessory nodules cortex & 36 \\
Accessory nodules medulla & 48 \\
Hyperemia cortex & 40 \\
Hemorrhage & 3 \\
Hyaline bodies & 11 \\
Amyloidosis & 4 \\
Calcification & 7 \\
Pigment & 87 \\
Hemosiderin & 15 \\
Cortical atrophy & 1 \\
Inflammatory cells cortex/medulla & $71 / 14$ \\
Adrenalitis & 9 \\
Necrosis & 3 \\
Cortical adenoma & 4 \\
Pheochromocytoma & 1 \\
Metastases & 6 lymphoma, 4 carcinoma $)$ \\
\hline
\end{tabular}

Table 7. Dystrophic changes and age of dogs.

\begin{tabular}{|c|c|c|c|c|c|}
\hline Age group & Lipid cortex & Lipid medulla & Hemosiderin cortex & Hemosiderin medulla & Calcium medulla \\
\hline$<0.5$ y $(6)$ & $0(0 \%)$ & $0(\%)$ & $0(\%)$ & $0(\%)$ & $0(\%)$ \\
\hline $0.5-6$ y (32) & 26 (81\%) & 3 (9\%) & 2 (6\%) & $0(0 \%)$ & $1(3 \%)$ \\
\hline 7 - 13 y (53) & 52 (98\%) & 11 (21\%) & $8(15 \%)$ & 7 (13\%) & 3 (6\%) \\
\hline$>13$ y (9) & $9(100 \%)$ & $3(33 \%)$ & $5(56 \%)$ & $2(22 \%)$ & $3(33 \%)$ \\
\hline
\end{tabular}

n number of animals.

Table 8. Dystrophic changes and size of dogs.

\begin{tabular}{cccccc}
\hline Age group & $\begin{array}{c}\text { Lipid pigment } \\
\text { cortex }\end{array}$ & $\begin{array}{c}\text { Lipid pigment } \\
\text { medulla }\end{array}$ & Hemosiderin cortex & $\begin{array}{c}\text { Hemosiderin } \\
\text { medulla }\end{array}$ & $\begin{array}{c}\text { Calcium deposition } \\
\text { medulla }\end{array}$ \\
\hline$\leq 10 \mathrm{~kg}(21)$ & $18(86 \%)$ & $9(43 \%)$ & $4(19 \%)$ & $2(10 \%)$ & $3(14 \%)$ \\
$10-20 \mathrm{~kg}(14)$ & $12(86 \%)$ & $4(29 \%)$ & $4(29 \%)$ & $2(14 \%)$ & $2(14 \%)$ \\
$\leq 20 \mathrm{~kg}(35)$ & $30(86 \%)$ & $13(37 \%)$ & $8(23 \%)$ & $4(11 \%)$ & $5(14 \%)$ \\
$>20 \mathrm{~kg}(61)$ & $58(95 \%)$ & $4(7 \%)$ & $7(11 \%)$ & $6(10 \%)$ & $2(3 \%)$ \\
\hline
\end{tabular}

n number of animals. 


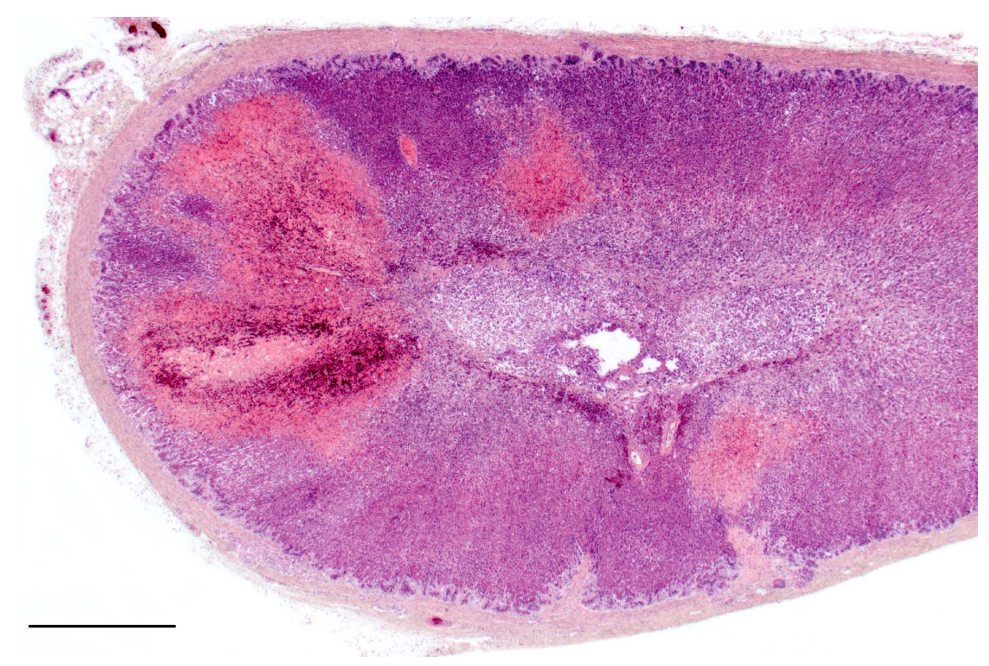

Figure 7. Adrenal cortical necrosis, dog, H\&E stain, bar $1 \mathrm{~mm}$.

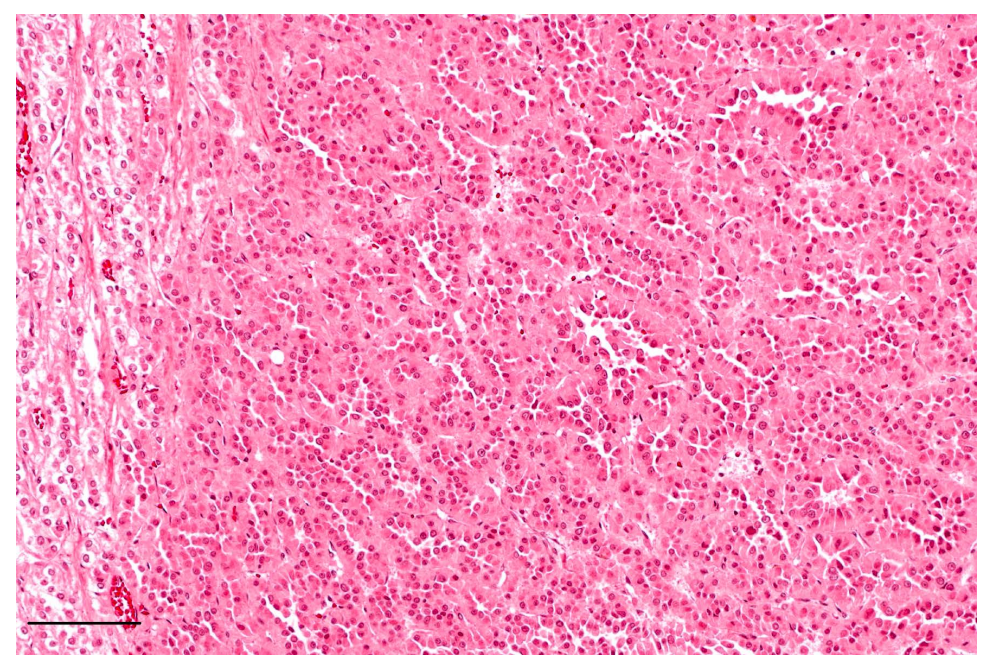

Figure 8. Pheochromocytoma, dog, H\&E stain, bar $100 \mu \mathrm{m}$.

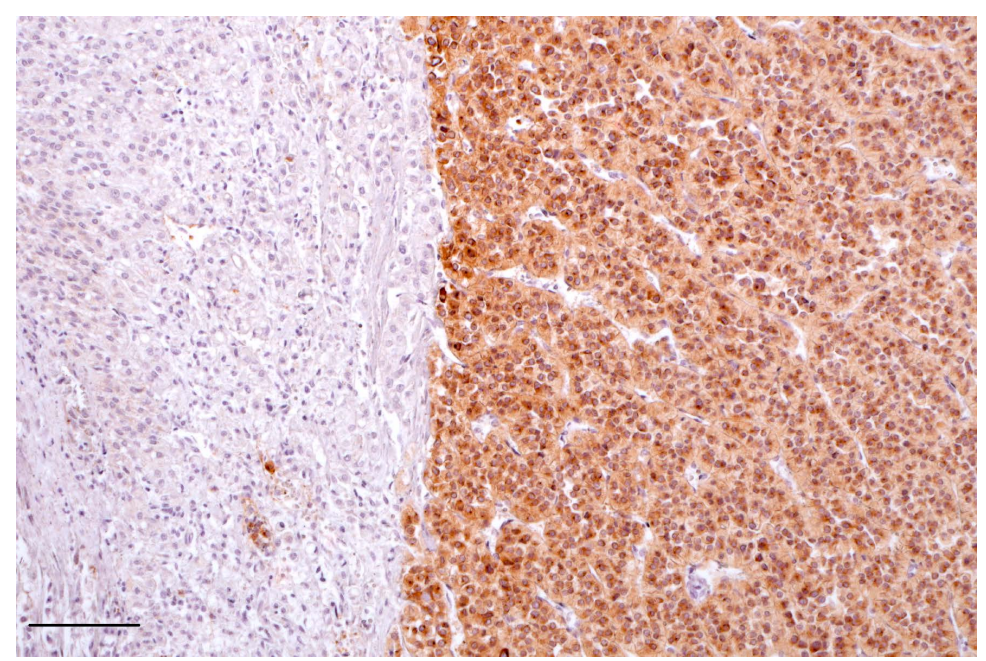

Figure 9. Pheochromocytoma, dog, immunohistochemistry anti-synaptophysin, DAB, hemalaun counterstain, bar $100 \mu \mathrm{m}$. 
Table 9. Proliferative changes and age of dogs.

\begin{tabular}{cccccc}
\hline Age group & Tumour anywhere & $\begin{array}{c}\text { Accessory nodules } \\
\text { capsule }\end{array}$ & $\begin{array}{c}\text { Accessory nodules } \\
\text { cortex }\end{array}$ & $\begin{array}{c}\text { Accessory nodules } \\
\text { medulla }\end{array}$ & $\begin{array}{c}\text { Cortical } \\
\text { hyperplasia }\end{array}$ \\
\hline$<0.5$ years $(6)$ & $0(0 \%)$ & $6(100 \%)$ & $1(17 \%)$ & $0(0 \%)$ & $0(0 \%)$ \\
0.5 - 6 years $(32)$ & $3(9 \%)$ & $32(100 \%)$ & $6(19 \%)$ & $15(47 \%)$ & $0(0 \%)$ \\
7 - 13 years (53) & $33(62 \%)$ & $53(100 \%)$ & $23(43 \%)$ & $27(51 \%)$ & $0(0 \%)$ \\
$>13$ years $(9)$ & $7(78 \%)$ & $9(100 \%)$ & $6(67 \%)$ & $6(67 \%)$ & $0(0 \%)$ \\
\hline
\end{tabular}

n number of animals.

The size of the animal correlated with the occurrence of neoplastic diseases anywhere in the body where larger animals more frequently exhibited malignant tumors (53\% of animals over $20 \mathrm{~kg}$ vs. $31 \%$ of dogs up to $20 \mathrm{~kg}$, $r_{\mathrm{P}}=-0.221, \mathrm{p}=0.032, \chi^{2}$ test $\mathrm{p}=0.032$, Mann-Whitney U-test $\mathrm{p}=0.033$; Table 9).

\section{Discussion}

In the majority of cats and dogs, infectious diseases and tumors were the main cause of death or euthanasia. Sixty-four percent of the cats and $26 \%$ of the dogs examined suffered from infectious diseases, and $23 \%$ of the cats and $45 \%$ of the dogs exhibited tumors anywhere in the body.

In the present study, a plethora of histological changes were documented in the adrenals of cats and dogs, some of which were dependent on age or gender.

In cats, dystrophic/degenerative changes were the most frequent histological findings of the adrenals, including cholesterol crystals, pigment deposition and mineralization. Finely granular to coarse mineralization of the adrenals and the fibrous capsule was observed in $38 \%$ of the feline adrenals and in only $7 \%$ of the canine adrenals, which is consistent with reports from the literature [2] [4]. There was a weak to moderate correlation of dystrophic/degenerative changes and age in cats, however, mineralization was also found in adrenals of kitten and cats less than 6 months of age (this study, [5]). According to earlier reports and as suggested by the present study, the mineralization is dystrophic in nature but rarely associated with overt adrenalitis [6]-[8]. However, mineralization weakly correlated with inflammatory cell infiltration of the adrenal cortex. In one feline adrenal of the present study, mineralization was associated with purulent inflammation. In early stages of mineralization, finely granular intracellular deposits appeared adjacent to apoptotic/necrotic cells. Deposition of crystals resembling cholesterol was strongly linked to mineralization of the adrenal cortex and is suggested to precede mineralization. Cholesterol is been produced by adrenal cortical cells and may form birefringent crystals which present as diffuse luminescence in unfixed frozen sections of cat adrenals. After mounting, birefringent crystals gradually appear in other species as well and a maximum of crystals appears in formalin-fixed gelatin-embedded tissue [9]. Pigment deposition in adrenal cortical cells, mainly the zona reticularis, was found in the majority of feline adrenals examined and most likely accounts for lipofuscin. It has recently been demonstrated, that adrenal cells undergo lineage conversion from glomerulosa to fasciculata cells with inward migration of the cells (migration theory) [10]. Other authors suggest that a stem/progenitor cells exist in a zone between glomerulosa and fasciculata cells which give rise to cortical cells (undifferentiated zone) and that cells migrate centripetally with aging [11] [12]. Therefore, zona reticularis cells may be considered the oldest adrenal cortical cells, giving an explanation why lipofuscin is present in reticularis cells but not glomerulosa cells. In addition, another type of pigment was observed in feline zona glomerulosa cells which also appeared golden-brown in the H\&E stain and did not react positive using Turnbull staining. Unlike lipofuscin pigment of the zona reticularis cells, which stained olive green, the pigment in zona glomerulosa stained blue in the Giemsa stain. In humans, hemosiderin storage may be seen in glomerulosa cells in course of general hemochromatosis but since the pigment did not stain positive with Turnbull stain, the pigment is most likely another type of lipofuscin. Lipid containing pigment deposition was also a common finding (87\%) in dogs and increased with age, as in the cats examined in this study, as well as in horses and rats [13].

Adrenal amyloid deposition was observed in three cats in the zona fasciculata and reticularis. One cat showed severe generalized amyloidosis. Four dogs with primary AA-amyloidosis, a hereditary type of amyloidosis that appears in American Shar-Pei breeds, exhibited adrenal involvement [14]. In humans, amyloid deposits are found in $68 \%$ of autopsy cases and are thought to be associated with aging. The human amyloid is composed of 
serum amyloid $\mathrm{P}$ and amyloid A protein [15].

Independent of the age, the majority of cats exhibited accessory cortical nodules in close association to the adrenal capsule, consisting of zona glomerulosa and fasciculata cells, surrounded by fibrous septa of the capsule. Likewise, almost all dogs examined (99/101) exhibited capsule associated nodules, containing zona glomerulosa and fasciculata cells. The number and size of the capsular nodules seemed to increase with age of the dogs.

Accessory nodules in the cortex or medulla, consisting of zona fasciculata and reticularis cells without a fibrous capsule were detected in about $30 \%$ of the cats and almost $50 \%$ of the dogs examined and the occurrence of accessory nodules in the cortex correlated with age in both species. In dogs, accessory cortical nodules are described in elderly dogs over 10 years of age. Histologically, the canine nodules contain abundant lipid vacuoles as well as lipofuscin [16]. In the present study, lipofuscin was also observed in accessory nodules in the adrenal cortex of cats but the cells of the nodules not regularly stored increased amounts of lipids. Adrenocortical nodules were distinguished from tumors by lack of a fibrous capsule, size, multiplicity and compression of the adjacent parenchyma [16]. The nodules are thought to develop as regenerative attempt due to involution of ageing and to compensate for malfunctioning adrenal cortical tissue [16], however, we also observed capsular nodules in animals under 0.5 years of age. The appearance of cortical nodules was found to correlate to age related vascular changes in humans and was therefore suggested to result from loss of cortical tissue due to focal ischemia [15] [17] [18]. The fact that the appearance of accessory nodules in the cortex was linked to cell death in the present study supports this suggestion. In immature baboons, adrenal cortical nodules were considered as mesenchymal rests separated during embryonic migration [19]. The accessory cortical nodules in young children are thought to arise from precursor cells that are located within connective tissue [20].

Hyaline globules or shock bodies were observed mainly in adrenal medullary and zona fasciculata vessels of $30 \%$ of the cats but only $10 \%$ of the dogs examined. In man, shock bodies are observed in the kidneys and liver sinusoids due to shock of different etiologies. For example, shock bodies develop within 1 - 2 hours after onset of inflammatory reaction due to skin burns [21], in association with hypovolemic and septic shock, pancreatitis, and due to brain trauma [22] [23]. The hyaline microthrombi are thought to develop as morphological sign of disturbed microcirculation and in intra vital hemostasis, alongside increased clotting e.g. due to thromboplastin release [24]. There is no evidence from literature of shock bodies in the adrenal gland. Eighty percent of the cats with adrenal shock bodies suffered from an infectious disease, mostly Parvo, Corona (FIP), Herpes and Calicivirus (rhinopneumonitis) infection. Parvo virus enteritis is thought to cause disseminated intravasal clotting (DIC) due to endotoxin uptake from the gut [25]. Mutated corona virus, which replicates in macrophages, is also suspected to cause DIC [26]. In the other cats with adrenal shock bodies, different inflammatory and infectious diseases were diagnosed. In seven of eleven cats with shock bodies and without evidence for infectious disease, either cardiac or traumatic shock was diagnosed, the remaining four cats suffered from malignant lymphoma. Half of the cats with shock bodies were euthanized, which could also lead to the development of microthrombi. Five of the eleven dogs with shock bodies exhibited inflammatory and infectious diseases, four exhibited tumors, one died due to cardiac shock during castration and one died from autoimmune hemolytic anemia.

About $20 \%$ of the cats and $40 \%$ of the dogs showed adrenal hyperemia and $9 \%$ of the cats and only $3 \%$ dogs showed cortical hemorrhage. Most cats with adrenal hemorrhage suffered from an infectious/inflammatory disease. In humans, adrenal hemorrhage is diagnosed in up to $1 \%$ of autopsy cases and is associated with bacterial infection, sepsis, burns, cardiac failure and anticoagulant therapy. When adrenal hemorrhage and acute adrenal insufficiency occur in children it is called Waterhouse-Friderichsen syndrome. Meningococcus (Neisseria meningitides), Pseudomonas, Streptococcus pneumoniae and Haemophilus influenza infections may lead to this disease of children [15].

Inflammatory cell infiltration of the adrenal cortex was diagnosed in 38 and of the medulla in 12 cats. Both purulent and non-purulent adrenalitis was diagnosed in almost equal numbers. In two thirds of the cats, an inflammatory disease was diagnosed. Half of the cats with corona virus infection (FIP) showed adrenal gland involvement. Although adrenalitis was diagnosed in 9 dogs only, unspecific inflammatory cell infiltrates were detected in the cortex of 72 dogs, in both cortex and medulla of fourteen and in the medulla of two dogs. Eosinophilic adrenalitis was diagnosed in one Chihuahua with pneumonia and in four cats, three of which showed bilateral eosinophilic infiltration of the medulla. In humans, focal adrenalitis is common and diagnosed in $50 \%$ of the autopsy cases [15].

No primary adrenal tumors were observed in cats but the organ was involved in tumor spread of malignant lymphoma and one cat each exhibited metastases of pancreatic and lung carcinoma. The incidence of adrenal 
tumors in cats is lower than that of dogs. Surveys including approximately 1000 cats failed to identify adrenal neoplasia [27]. Four dogs of the present study exhibited adrenal adenoma and one showed pheochromocytoma. In five of nine dogs with malignant lymphoma, the adrenals were involved in neoplastic disease. Adenocarcinoma metastases of unknown origin were found in adrenals of three and of a mamma carcinoma in one dog. In humans, lung and mamma carcinoma metastases are the most frequent metastases of the adrenals, less common are renal cell, gastric and colon carcinomas [15].

\section{Conclusion}

In summary we frequently observed accessory cortical nodules, pigment (lipofuscin) and fibrous tissue in adrenals of both dogs and cats in an age-dependent manner. Clinical relevant primary adrenal diseases were rarely observed.

\section{Acknowledgements}

This publication is dedicated to Professor Dr. Dr. H.C. Erwin Dahme on occasion of his $90^{\text {th }}$ birthday.

\section{References}

[1] Gunn-Moore, D. (2005) Feline Endocrinopathies. Veterinary Clinics of North America: Small Animal Practice, 35, 171-210. http://dx.doi.org/10.1016/j.cvsm.2004.09.002

[2] Capen, C.C. (2007) Endocrine Glands. In: Maxie, M.G., Ed., Jubb, Kennedy \& Palmer's Pathology of Domestic Animals, Vol. 3, Elsevier, Philadelphia, 326-428.

[3] Hermanns, W., Liebig, K. and Schulz, L.C. (1981) Postembedding Immunohistochemical Demonstration of Antigen in Experimental Polyarthritis Using Plastic Embedded Whole Joints. Histochemistry, 73, 439-446. http://dx.doi.org/10.1007/BF00495658

[4] Brüschweiler, H.P. (1925) Über die Verkalkungen der Nebenniere der Katze. Virchows Archiv für Pathologische Anatomie und Physiologie und für Klinische Medizin, 255, 494-503. http://dx.doi.org/10.1007/bf01891696

[5] Bögli, W. (1928) Verkalkungen und Nekrosen in den Nebennieren von Katzen unter einem halben Jahr. In: Vetsuisse-Fakultät, Vol. Dr. med. vet., Universität Bern, Switzerland.

[6] Marine, D. (1926) Calcification of the Suprarenal Glands of Cats. Journal of Experimental Medicine, 43, 495-499. http://dx.doi.org/10.1084/jem.43.4.495

[7] Ross, M.A., Gainer, J.H. and Innes, J.R. (1955) Dystrophic Calcification in the Adrenal Glands of Monkeys, Cats, and Dogs. A.M.A. Archives of Pathology, 60, 655-662.

[8] Oettel, M. and Rittenbach, P. (1966) Calcification of the Adrenal Glands in the Domestic Cat. Wiener tierarztliche Monatsschrift, 53, 643-653.

[9] Yoffey, J.M. and Baxter, J.S. (1947) The Formation of Birefringent Crystals in the Suprarenal Cortex. Journal of Anatomy, 81, 335-342, 334.

[10] Freedman, B.D., Kempna, P.B., Carlone, D.L., Shah, M.S., Guagliardo, N.A., Barrett, P.Q., Gomez-Sanchez, C.E., Majzoub, J.A. and Breault, D.T. (2013) Adrenocortical Zonation Results from Lineage Conversion of Differentiated Zona Glomerulosa Cells. Developmental Cell, 26, 666-673. http://dx.doi.org/10.1016/j.devcel.2013.07.016

[11] Mitani, F., Mukai, K., Miyamoto, H., Suematsu, M. and Ishimura, Y. (2003) The Undifferentiated Cell Zone Is a Stem Cell Zone in Adult Rat Adrenal Cortex. Biochimica et Biophysica Acta, 1619, 317-324. http://dx.doi.org/10.1016/S0304-4165(02)00490-7

[12] Kim, A.C., Barlaskar, F.M., Heaton, J.H., Else, T., Kelly, V.R., Krill, K.T., Scheys, J.O., Simon, D.P., Trovato, A., Yang, W.H. and Hammer, G.D. (2009) In Search of Adrenocortical Stem and Progenitor Cells. Endocrine Reviews, 30, 241-263. http://dx.doi.org/10.1210/er.2008-0039

[13] Matthias, D. (1968) Die Nebennieren. Glandulae suprarenales, chromaffines Gewebe. In: Dobberstein, J., Pallaske, G. and Stünzi, H., Eds, Handbuch der speziellen pathologischen Anatomie der Haustiere, Vol. 3, Endokrine Drüsen, Nervensysteme, Sinnesorgane, Paul Parey, Hamburg, 49-88.

[14] Kamenica, K. and Hermanns, W. (2006) Generalisierte Amyloidose bei einer Shar-Pei-Zuchthündin. Tierärztliche Praxis Kleintiere, 34, 108-111.

[15] Lloyd, R.V., Douglas, B.R. and Young, W.F. (2002) Atlas of Nontumor Pathology Endocrine Diseases. Armed Forces Institute of Pathology, Washington DC.

[16] Commichau, K. (1927) Über die knotigen Hyperplasien der Nebennierenrinde bei Hunden, sogenannten corticalen 
Hypernephrome. Journal of Cancer Research and Clinical Oncology, 25, 253-290. http://dx.doi.org/10.1007/bf02122321

[17] Dobbie, J.W. (1969) Adrenocortical Nodular Hyperplasia: The Ageing Adrenal. The Journal of Pathology, 99, 1-18. http://dx.doi.org/10.1002/path.1710990102

[18] McNicol, A.M. (2008) A Diagnostic Approach to Adrenal Cortical Lesions. Endocrine Pathology, 19, $241-251$. http://dx.doi.org/10.1007/s12022-008-9055-x

[19] Skelton-Stroud, P.N. and Ishmael, J. (1985) Adrenal Lesions in the Baboon (Papio spp). Veterinary Pathology, 22, 141-146.

[20] Gruenwald, P. (1946) Embryonic and Postnatal Development of the Adrenal Cortex, Particularly the Zona Glomerulosa and Accessory Nodules. Anatomical Record, 95, 391-421. http://dx.doi.org/10.1002/ar.1090950404

[21] Cottier, H. (1980) Pathogenese. Ein Handbuch für ärztliche Fortbildung. Springer Verlag, Berlin. http://dx.doi.org/10.1007/978-3-642-67213-2

[22] Oehmichen, M., Pedal, I., Schmidt, V. and Schlote, W. (1986) Form Variants of Globular Hyaline Microthrombi. Light Microscopy, Immunohistochemical and Scanning and Transmission Electron Microscopy Observations. Zeitschrift fur Rechtsmedizin, 97, 29-40.

[23] Lafuente, J.V. and Cervos-Navarro, J. (1999) Craniocerebral Trauma Induces Hemorheological Disturbances. Journal of Neurotrauma, 16, 425-430. http://dx.doi.org/10.1089/neu.1999.16.425

[24] Bleyl, U. and Rossner, J.A. (1976) Globular Hyaline Microthrombi-Their Nature and Morphogenesis. Virchows Archiv A, Pathological Anatomy and Histology, 370, 113-128. http://dx.doi.org/10.1007/BF00430808

[25] Sellon, R.K. (2005) Canine Viral Diseases. In: Ettinger, S.J. and Feldmann, E.C., Eds, Textbook of Veterinary Internal Medicine, Elsevier/Saunders, St. Louis, 646-652.

[26] Foley, J.E. (2005) Feline Infectious Peritonitis and Feline Enteric Corona Virus. In: Ettinger, S.J. and Feldmann, E.C., Eds, Textbook of Veterinary Internal Medicine, Elsevier/Saunders, St. Louis, 663-666.

[27] Myers 3rd, N.C. (1997) Adrenal Incidentalomas. Diagnostic Workup of the Incidentally Discovered Adrenal Mass. Veterinary Clinics of North America: Small Animal Practice, 27, 381-399. http://dx.doi.org/10.1016/S0195-5616(97)50038-6

\section{Submit or recommend next manuscript to SCIRP and we will provide best service for you:}

Accepting pre-submission inquiries through Email, Facebook, Linkedin, Twitter, etc A wide selection of journals (inclusive of 9 subjects, more than 200 journals)

Providing a 24-hour high-quality service

User-friendly online submission system

Fair and swift peer-review system

Efficient typesetting and proofreading procedure

Display of the result of downloads and visits, as well as the number of cited articles

Maximum dissemination of your research work

Submit your manuscript at: http://papersubmission.scirp.org/ 